\title{
Native versus non-native invasions: similarities and differences in the biodiversity impacts of Pinus contorta in introduced and native ranges
}

\author{
Authors: Kimberly Taylor, Bruce Maxwell, Aníbel \\ Pauchard, Martin A. Nuñez, and Lisa Rew
}

This is the peer reviewed version of the following article: as cited below, which has been published in final form in Diversity and Distributions at https://dx.doi.org/10.1111/ddi.12419. This article may be used for non-commercial purposes in accordance with Wiley Terms and Conditions for Self-Archiving.

Taylor, Kimberley T., Bruce D. Maxwell, Aníbal Pauchard, Martin A. Nuñez, and Lisa J. Rew. "Native versus non-native invasions: similarities and differences in the biodiversity impacts of Pinus contorta in introduced and native ranges." Diversity and Distributions 22, no. 5 (January 2016): 578-588.

Made available through Montana State University's ScholarWorks scholarworks. montana.edu 


\title{
Native versus non-native invasions: similarities and differences in the biodiversity impacts of Pinus contorta in introduced and native ranges
}

\author{
Kimberley T. Taylor ${ }^{1}$, Bruce D. Maxwell ${ }^{1}$, Aníbal Pauchard ${ }^{2}$, Martin A. Nuñez ${ }^{3}$ and Lisa J. Rew ${ }^{1}$ \\ ${ }^{1}$ Land Resources and Environmental Sciences Department, Montana State University, Bozeman, MT 59717, USA, \\ ${ }^{2}$ Facultad de Ciencias Forestales, Universidad de Concepción, Casilla 160-C, Concepción, Chile \& Institute of Ecology and \\ Biodiversity (IEB), Chile, \\ ${ }^{3}$ Grupo de Ecologia de Invasiones, INIBIOMA, CONICET, Universidad Nacional del Comahue, Quintral 1250, San Carlos \\ de Bariloche CP 8400, Argentina
}

\begin{abstract}
Aim To determine whether one of the most invasive pine species introduced to the Southern Hemisphere, Pinus contorta, has changed plant species richness, composition, diversity, and litter depth where it has invaded into native open forest, shrub steppe and grassland communities and to assess whether changes were similar in its native and introduced ranges.
\end{abstract}

Location Río Negro Province, Argentina; Aysén and Araucanía Regions, Chile; Greater Yellowstone Ecosystem, USA.

Methods We measured changes in plant species richness, species composition and cover, diversity, and litter depth associated with increasing P. contorta tree cover along the invasion front at three sites in the introduced range (Argentina and Chile) and one in the native range (Montana, USA).

\begin{abstract}
Results Plant species richness and cover generally declined with increasing P. contorta canopy cover, at similar rates in both the introduced and native ranges. However, plant cover was not affected by P. contorta in a forested setting in the introduced range. P. contorta invasion explained more of the decline in species richness in the introduced than native range. Native species composition changed more strongly across the invasion gradient in the introduced than native range. Litter depth increased more rapidly with $\mathrm{P}$. contorta cover in the native than introduced range.

Main conclusions Our results highlight the potential of pines to alter plant communities whether encroaching from forests in the native range or from plantations in the introduced range. Species richness and plant cover declined in both settings; however, individual species abundance and species composition were more impacted in the introduced range than in the native range. We suggest that invading trees have a greater capacity to cause ecological impacts in their introduced than in their native range, particularly where they represent a novel life-form.
\end{abstract}

Keywords biogeography, biological invasions, invasion impact, pine invasion, Pinus contorta, tree invasions.

\section{INTRODUCTION}

Invasive plants, particularly invasive trees, are well known to have significant impacts on native biodiversity (e.g. Gaertner et al., 2009; Camarillo et al., 2015; Constán-Nava et al., 2015; Lazzaro et al., 2015; Shackleton et al., 2015). Less known, however, is whether the impact differs depending on whether the invasion occurs in an introduced range or in the species' native range. Many plant species grow larger and more densely in their introduced than in their native range (Parker et al., 2013), which would suggest that the potential for negative impacts through competition would be greater 
in the introduced range (Blossey \& Notzold, 1995). Invasive species can also alter ecosystems through the introduction of novel traits or life-forms (Levine et al., 2003). When the introduction of a novel trait to the new system causes invader impacts, similar impacts would not be expected in the native range where the trait was not novel. Generally, native species are less likely to spread into adjacent habitats than introduced species (Simberloff et al., 2012). However, few studies have compared the impacts of a species invading new areas in both its native and introduced range. Here, we examine the influence of Pinus contorta invasion on plant biodiversity in both its native and introduced ranges when it encroaches into adjacent habitat.

Biogeographic studies that have examined invasive plant impacts on biodiversity have found that the presence of the invader is negatively correlated with native plant species richness or biomass in the introduced range, but neutral or positive correlations were noted in the native range (Inderjit et al., 2011; Callaway et al., 2012; Kaur et al., 2012; Shah et al., 2014). With one exception (Shah et al., 2014), these studies examined plants that were not actively invading adjacent communities in their native range. They also did not measure species richness along an abundance gradient of the study species, but instead compared areas with and without the species present.

Several mechanisms have been suggested to explain differences in invader impacts between the native and introduced ranges. These mechanisms include the following: stronger competitive effects of invading species in the introduced range than in the native range (Callaway \& Aschehoug, 2000; Ni et al., 2010); evolution of increased growth rates in the introduced range (Blossey \& Notzold, 1995; Siemann \& Rogers, 2001); differences in plant-soil feedbacks between ranges (Klironomos, 2002); allelopathy in the litter and soil (Callaway et al., 2008; Thorpe et al., 2009; Ni et al., 2010; Kaur et al., 2012); differences in volatile organic compounds that affect neighbouring plant mortality between ranges (Inderjit et al., 2011); and altered soil nitrogen cycling (Thorpe \& Callaway, 2011). Many invader impacts are caused by alteration of the microenvironment, changes in litter abundance or composition, or changes in soil microbial communities (Skurski et al., 2014), although it is unclear how these processes differ between invasions of new habitat in the native versus in the introduced ranges. Other studies have suggested that invader impacts can increase when multiple invasive species facilitate each other (e.g. exotic fungus promoting growth of exotic pines), creating an invasional meltdown' (Simberloff \& Von Holle, 1999; Nuñez et al., 2013; Dickie et al., 2014).

Pines (genus Pinus) are an ideal group to examine whether invasion impacts are similar in the native and introduced ranges. Pines are widely distributed across the Northern Hemisphere, but there are no native pines in the Southern Hemisphere outside of a small area in Indonesia (Rundel et al., 2014). In the 19th and 20th centuries, pines were introduced throughout the Southern Hemisphere for forestry
(Richardson \& Higgins, 1998). Currently, in both the introduced and native ranges, pines are encroaching into grasslands and shrublands (Richardson \& Bond, 1991; Jakubos \& Romme, 1993; Simberloff et al., 2010). Generally, pine seeds are widely dispersed by wind and the seedlings are good colonizers of grasslands and shrublands (Richardson, 1998). In areas where they have been introduced and escaped, pines have had measurable impacts on native biodiversity (Ledgard \& Paul, 2008; Pawson et al., 2010; Urrutia et al., 2013), nutrient cycling and soil microbial communities (Dehlin et al., 2008; Dickie et al., 2011, 2014), and hydrological cycles (Farley et al., 2005; Fernandez et al., 2009). Pinus contorta Dougl. (lodgepole pine), which is native to western North America, has traits that lead to high invasive potential (low seed mass, short juvenile period, and short interval between large seed crops; Rejmánek \& Richardson, 1996), and only three pine species introduced to the Southern Hemisphere have been found to invade more regions than P. contorta (of 24 species; Rejmánek \& Richardson, 2013). Pinus contorta was initially introduced for soil erosion control in New Zealand and Patagonia and has since been planted for forestry purposes.

Pinus contorta and other exotic pine species have been associated with biodiversity declines in their introduced ranges both within plantations (Nilsson et al., 2008; Paritsis \& Aizen, 2008) and where they have invaded into surrounding natural habitat (Ledgard \& Paul, 2008; Dickie et al., 2011; Steers et al., 2013; Urrutia et al., 2013). Impacts have also been observed in the native range where conifer encroachment (hereafter called invasion) into meadows in western North America has altered soil biogeochemical cycles and microbial communities (Griffiths et al., 2005) and lowered meadow plant species diversity (Haugo \& Halpern, 2007). Increased density of native slash pines (Pinus elliottii) due to fire suppression in the south-east USA was also correlated with lower understorey plant diversity (Brewer, 1998).

Thus, examining P. contorta invasions into grassland and shrubland plant communities provides a unique opportunity to compare their impacts on plant diversity between the native and introduced ranges. While impacts have been observed in both ranges, $P$. contorta invades more densely and grows faster in the introduced than native range (Taylor et al., 2016). In addition, Southern Hemisphere plants have no evolutionary history of interacting with species in the Pinaceae. Therefore, we expected that $P$. contorta invasions would have a greater impact on plant communities in the introduced than native range, especially where pines add new functional traits (deep litter with slow decay, continuous tree canopy, and unique mycorrhizal associations) to the community (Rundel et al., 2014).

The consequences that invasive species have on communities vary (Hulme et al., 2013) as a function of the existing species composition and environmental conditions (Ehrenfeld, 2003). Therefore, it is important to study invasion across various sites with different environmental characteristics (Hulme et al., 2013; Kumschick et al., 2015). Previous 
studies have not compared the biodiversity of plant communities across a gradient of pine invasion in both the native and introduced range, and few have examined how the influence of an invader relates to its abundance (Vilà et al., 2011). In this paper, we examine changes in plant communities and litter depth across a range of invasion intensities (as measured by $P$. contorta cover) at three sites in Patagonia (Argentina and Chile) and one site in the native range (Montana, USA). The specific objectives of this study were as follows: (1) to determine the relationship between changes in $P$. contorta cover and plant species richness, cover, composition, and diversity in native and introduced regions; (2) to assess whether certain life-forms within the native communities were correlated with P. contorta invasion; (3) to determine whether litter depth (a potentially important transformative trait) differs across the $P$. contorta invasion gradients; and (4) to assess the relative importance of litter abundance versus $P$. contorta cover in explaining variation in species richness and plant cover. We hypothesized that species richness, plant cover, and diversity would decline with increasing P. contorta cover at a faster rate in the introduced range than in the native range. We also expected that litter depth would increase with increasing $P$. contorta cover at all sites and would additionally contribute to reduced native species cover.

\section{METHODS}

\section{Study sites}

Study sites included locations in Bariloche and El Bolsón, Argentina (AR); Coyhaique Alto, Chile (CL1); Malalcahuello, Chile (CL2; all introduced range); and south-western Montana, United States of America (USA; native range; see Fig. S1 and Table S1 in Supporting Information for climate and other environmental characteristics of all sites). The sites in Argentina (AR) were combined because they had similar shrub steppe communities, dominated by Festuca pallescens, Mulinum spinosum and Acaena spp. (see Table S2 for full species lists). Adjacent $P$. contorta plantations were established between 20 and 35 years ago. Coyhaique Alto, Chile (CL1), was a grass steppe community dominated by Festuca pallescens, Baccharis magellanicum and Acaena intergerrima. The source P. contorta plantations at CL1 were 17-26 years old. The second site in Chile was located in the Reserva Nacional Malalcahuello (CL2) and was dominated by sparse Araucaria araucana forest with areas of Nothofagus antarctica and an understorey composed of Festuca scabriuscula, Chusquea culeou and Gaultheria species. Here, the source populations were trial forestry plots planted 43 years ago (Peña et al., 2008; Urrutia et al., 2013). The site in Montana (USA) included sagebrush steppe dominated by Artemisia tridentata, Festuca idahoensis and Stipa species. Most of the P. contorta encroachment into the sagebrush steppe at this site has occurred in the last 50 years (Patten, 1969). Pinus contorta encroachment into nearby grasslands has been attributed to long-term climatic change (Jakubos \& Romme, 1993), although encroachment is generally rare in this region. There was no evidence of recent fire in any site. Nomenclature follows Lesica (2012) for USA and Zuloaga et al. (2008) for Argentina and Chile.

\section{Field sampling}

Plots were randomly located within sites and stratified by $P$. contorta canopy cover. The $P$. contorta cover gradient was positively correlated with the age of invading trees and their distance from the seed source plantation or native forest. Non-invaded plots were constrained to areas dominated by vegetation types known to be invaded by $P$. contorta at these same sites (Peña et al., 2008; Langdon et al., 2010; Taylor et al., 2016).

Ocular canopy cover data were collected for every vascular plant species in each plot (five by five metres); every species had the potential to account for 100 percentage cover. In the only site with native trees (CL2), we did not include cover of overstorey tree species (mainly Araucaria araucana) in the analyses. At each plot, we estimated mean litter depth from five depth measurements. P. contorta canopy cover was recorded in the centre of each plot with a spherical densiometer. Sample sizes were 13 in AR, 20 in CL1, 19 in CL2 and 21 in USA, across a $P$. contorta canopy cover gradient from zero to nearly 100 percentage.

Studies that experimentally add an invasive plant and record impacts on plant communities over time are superior to the chronosequence approach that we took, but the years required for this type of experiment made it logistically unfeasible. Our sites were relatively homogenous and the invasions progressed uniformly from the plantations (Fig. S1), so we are confident that the main difference between invaded and non-invaded plots in any study site was largely a result of $P$. contorta presence. The continuous wave of invasion, as demonstrated by the decreasing age of trees with increasing distance from the plantation/forest edge (rather than patchy invasion), suggests that $P$. contorta establishment was not influenced by minor differences in local species composition or abundance (Pauchard A., pers. comm.).

\section{Statistical analysis}

We used P. contorta percentage cover as the explanatory variable in all analyses (Pawson et al., 2010). Relative species richness (percentage of maximum at that site) was modelled with linear regression as a function of $P$. contorta cover for each site individually. We used relative species richness to account for overall differences in richness between sites. Shannon diversity was calculated for each plot (Oksanen et al., 2013) and then modelled with linear regression as a function of $P$. contorta cover for each site individually. Additionally, data from all sites were combined and relative species richness and diversity were modelled as a function of 
P. contorta cover, site and their interaction to determine whether the rate of change of richness and diversity differed between sites.

Species composition at each site was examined by calculating the Bray-Curtis distance between plots based on all species cover (excluding P. contorta). Permutational multivariate analysis of variance (PERMANOVA) was used to determine whether $P$. contorta cover was significantly related to species composition as represented by the Bray-Curtis distances. Linear regression was used to model total plant cover, plant cover by life-form (cushion, grass, forb, shrub), exotic plant cover, and cover of each species individually in response to P. contorta cover for each site separately. A Poisson regression was used to model exotic species richness as a function of $P$. contorta cover for each site. Finally, total plant cover data from all sites were combined to test for differences in the relationship between $P$. contorta cover and total cover between sites. To control for differences between sites in overall productivity, relative total plant cover (cover of each plot divided by maximum plant cover at that site) was modelled with linear regression as a function of $P$. contorta cover, site and their interaction.

Two potential mechanisms by which $P$. contorta could influence plant communities are through an increase in shade (measured here as canopy cover) and an increase in persistent litter (measured as litter depth). To explore these possibilities, we first modelled litter depth as a function of $P$. contorta cover at each site individually and then in a model that combined data from all sites to determine differences in litter accumulation rates with $P$. contorta invasion between sites. We then modelled relative species richness (percentage of maximum), total plant cover and plant cover by life-form (grass, forb, shrub) as a function of both $P$. contorta cover and litter depth. We used commonality analysis (Ray-Mukherjee et al., 2014) to improve our interpretation of the multiple regression results, given the collinearity between $P$. contorta cover and litter depth $\left(R^{2}\right.$ between 0.16 and 0.62 , Table 1$)$. Commonality analysis separates the variance of the model $R^{2}$ into unique and shared effects of the predictors (Ray-Mukherjee et al., 2014). Commonality analysis allowed us to determine how much of the variance in the responses was explained by only $P$. contorta cover, only litter depth or both due to collinearity. All statistical analysis was performed in R ( $\mathrm{R}$ Core Team, 2014).

\section{RESULTS}

\section{Species richness and diversity}

Relative species richness declined with increasing $P$. contorta cover at all sites, but $P$. contorta cover explained more than twice the variance in species richness at the introduced sites than at the native site (Table 1; Fig. 1(a)). In the combined model, the rate of decline in relative species richness with increasing $P$. contorta cover did not differ between the USA (native range) and introduced range sites $\left(F_{3,65}=1.33\right.$,
Table 1 Results from models from each site of species richness, grass cover, forb cover, shrub cover, total plant cover and litter depth as a function of Pinus contorta cover. - indicates that that life-form was not present at the given site or the model was not significant at the alpha equals 0.05 level. $R^{2}$ is adjusted $R^{2}$.

Results from cushion plants were not shown because there was no significant relationship with Pinus contorta cover at any site $(P>0.05)$. See Fig. S1 and Table S1 for full site descriptions (AR, CL1, CL2, USA).

\begin{tabular}{|c|c|c|c|c|}
\hline & $\mathrm{AR}$ & CL1 & CL2 & USA \\
\hline \multicolumn{5}{|c|}{ Relative species richness } \\
\hline Cover & -0.492 & -0.484 & -0.394 & -0.219 \\
\hline $\mathrm{SE}$ & 0.119 & 0.11 & 0.118 & 0.094 \\
\hline$t$-value & -4.145 & -4.4 & -3.325 & -2.317 \\
\hline$P$-value & 0.002 & $<0.001$ & 0.004 & 0.032 \\
\hline$R^{2}$ & 0.57 & 0.49 & 0.359 & 0.18 \\
\hline \multicolumn{5}{|c|}{ Litter depth } \\
\hline Cover & 0.012 & 0.021 & 0.011 & 0.029 \\
\hline $\mathrm{SE}$ & 0.007 & 0.004 & 0.004 & 0.007 \\
\hline$t$-value & 1.823 & 5.696 & 2.840 & 4.385 \\
\hline$P$-value & 0.096 & $<0.001$ & 0.011 & $<0.001$ \\
\hline$R^{2}$ & - & 0.623 & 0.282 & 0.477 \\
\hline \multicolumn{5}{|c|}{ Grass cover } \\
\hline Cover & -0.042 & -0.176 & -0.201 & -0.061 \\
\hline SE & 0.013 & 0.069 & 0.063 & 0.105 \\
\hline$t$-value & -3.159 & -2.555 & -3.185 & -0.577 \\
\hline$P$-value & 0.009 & 0.02 & 0.005 & 0.571 \\
\hline$R^{2}$ & 0.428 & 0.225 & 0.337 & - \\
\hline \multicolumn{5}{|l|}{ Forb cover } \\
\hline Cover & -0.003 & -0.019 & -0.014 & -0.185 \\
\hline SE & 0.01 & 0.005 & 0.007 & 0.078 \\
\hline$t$-value & -0.316 & -3.993 & -1.997 & -2.376 \\
\hline$P$-value & 0.758 & 0.001 & 0.062 & 0.028 \\
\hline$R^{2}$ & - & 0.440 & - & 0.189 \\
\hline \multicolumn{5}{|c|}{ Shrub cover } \\
\hline Cover & -0.421 & - & 0.071 & -0.297 \\
\hline SE & 0.09 & - & 0.137 & 0.104 \\
\hline$t$-value & -4.668 & - & -0.514 & -2.859 \\
\hline$P$-value & $<0.001$ & - & 0.614 & 0.01 \\
\hline$R^{2}$ & 0.634 & - & - & 0.264 \\
\hline \multicolumn{5}{|l|}{ Total cover } \\
\hline Cover & -0.435 & -0.236 & -0.177 & -0.543 \\
\hline $\mathrm{SE}$ & 0.095 & 0.075 & 0.126 & 0.169 \\
\hline$t$-value & -4.571 & -3.158 & -1.406 & -3.208 \\
\hline$P$-value & $<0.001$ & 0.006 & 0.178 & 0.005 \\
\hline$R^{2}$ & 0.624 & 0.321 & - & 0.317 \\
\hline
\end{tabular}

$P=0.272$ ). There was a significant negative relationship between Shannon diversity and $P$. contorta cover at CL2 $(t=-2.4$, d.f. $=17, P=0.028)$ but no relationship at other sites.

\section{Plant composition}

Pinus contorta cover was significantly related to differences in species composition between plots within sites in both introduced and native ranges (Table 2). However, P. contorta cover explained twice as much of the similarity in species 


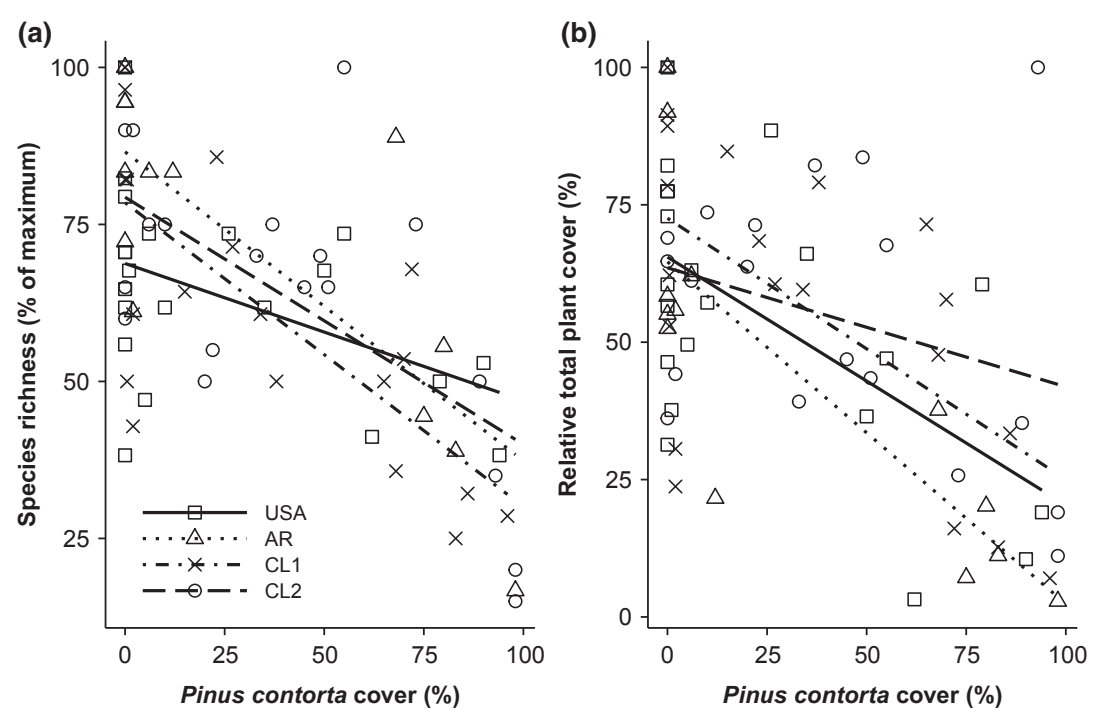

Figure 1 Relative species richness (a) and relative total plant cover (b) plotted against Pinus contorta cover (\%) for each site with the fitted line from the combined models containing all data from all sites. Statistically, the slopes of the lines do not differ between the native site (USA) and any introduced site (AR, CL1, CL2) for both relative species richness and relative total plant cover $(P>0.05)$. Solid line and squares represent USA, dotted line and triangles represent AR, dot dashed line and X's represent CL1, and long dashed line and circles represent CL2. See Fig. S1 and Table S1 for full site descriptions (AR, CL1, CL2, USA).
Table 2 Results from the PERMANOVA (permutational multivariate analysis of variance) for each site that models BrayCurtis distance between plot species composition as a function of Pinus contorta cover. AR (shrubland), CL1 (grassland) and CL2 (open forest) are introduced range sites, and USA (shrubland) is the native range site. See Fig. S1 and Table S1 for full site descriptions.

\begin{tabular}{llc}
\hline & \multicolumn{2}{l}{$P$. contorta cover } \\
\cline { 2 - 3 } Site & $R^{2}$ & $P$-value \\
\hline AR & 0.31 & 0.001 \\
CL1 & 0.21 & 0.003 \\
CL2 & 0.12 & 0.023 \\
USA & 0.11 & 0.023 \\
\hline
\end{tabular}

composition between steppe plots in the introduced range (AR and CL1) than in the native range (USA; Table 2).

When examining relationships between $P$. contorta cover and individual species cover, we found that at all introduced sites most of the significant relationships $(P<0.05)$ were negative (Fig. 2; Table S3). In contrast, in the native range the only species (Poa palustris) that had a significant relationship with $P$. contorta cover had higher abundance in more highly invaded plots (Fig. 2; Table S3). At AR, P. contorta cover had a significant negative relationship with the cover of three native species ( $14 \%$ of the species present in at least three sampled plots), including the most frequently occurring shrub species (Mulinum spinosum). At CL1, P. contorta cover had a significant negative relationship with cover of fourteen species (37\% of the species present in at least three sampled plots), including the most common grass species Festuca pallescens (Fig. S2). Only the native Viola reichei had a significant positive relationship with $P$. contorta cover at CL1 (Fig. 2; Table S3). At CL2, P. contorta cover had a significant negative relationship with two species (7\% of species present in at least three plots), including the most common grass species (Festuca scabriuscula; Fig. S2).

\section{Changes in plant cover by life-form and origin}

Pinus contorta cover was negatively correlated with total plant cover at all sites except CL2 (Fig. 3; Table 1). In the combined model, the relationship between $P$. contorta cover and relative total cover did not differ between the native site (USA) and introduced sites $\left(F_{3,65}=1.27, P=0.293\right.$; Fig. 1$)$. Analysis of the sites separately showed $P$. contorta cover was negatively correlated with, grass cover at AR, CL1, and CL2 (Table 1), forb cover at CL1 and USA (Table 1), and shrub cover at USA and AR (Table 1).

Exotic species cover other than P. contorta was low $(<2 \%)$, although some exotic species were frequently present in sampled plots (e.g. Rumex acetosella in introduced range sites; Table S2). Seven exotic species were found at AR and CL1, three at CL2, and six at USA. Exotic plant cover decreased with increasing $P$. contorta cover at CL1 $\left(F_{1,18}=8.43\right.$, $P=0.010)$. Exotic cover at all other sites and exotic richness at all sites were not correlated with $P$. contorta cover ( $P>0.05$ for all comparisons).

\section{Relationship between $P$. contorta cover and litter depth}

Pinus contorta cover was positively correlated with litter depth at CL1, CL2 and USA but not at AR (Table 1; Fig. 4). The relationship between litter depth and P. contorta cover did not differ between USA and CL1 $(t=-1.02$, d.f. $=65$, $P=0.312)$, but litter depth increased more slowly with invasion at CL2 than at USA $(t=-2.33$, d.f. $=65, P=0.023$; Fig. 4). Litter included pine needles, but also dead material from native grasses and shrubs.

\section{Mechanism of impact}

Pinus contorta cover alone explained more of the variance in relative species richness and plant cover than did litter depth 


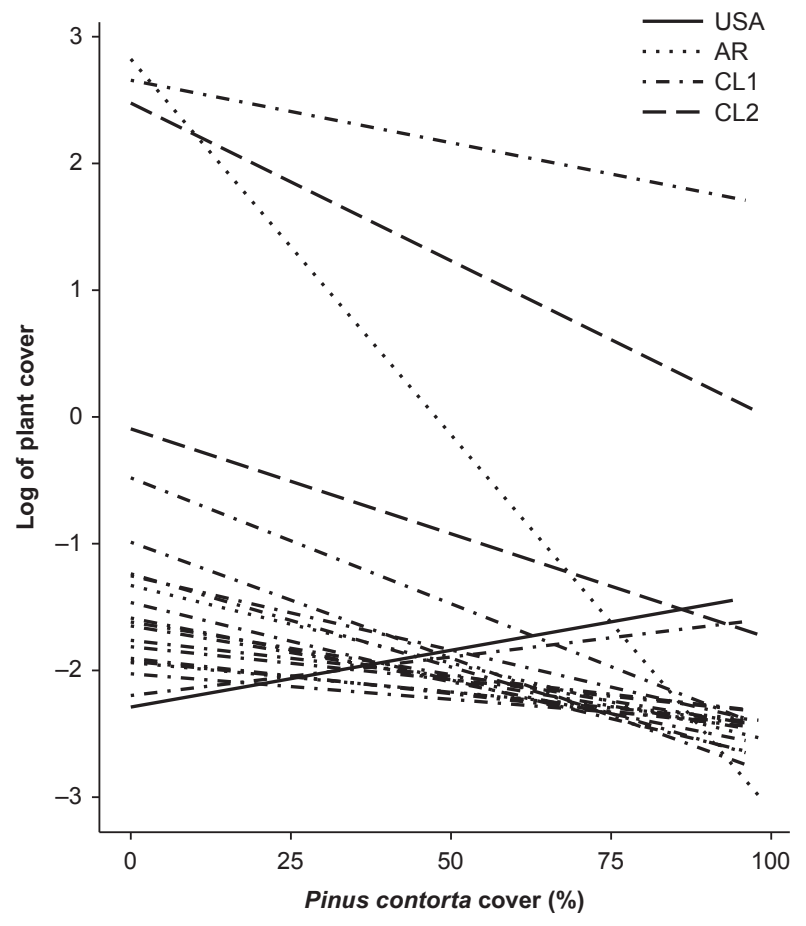

Figure 2 Fitted lines from linear models of the natural log of cover for all individual species as a function of Pinus contorta cover. Each line represents one species, and lines are only shown for species that had a significant relationship with Pinus contorta cover $(P<0.05)$. All species, their slopes, model $P$-values and sample sizes are reported in Table S3. Solid lines represent species found in the United States, dotted lines represent species found in AR, dot dashed lines represent species found in CL1, and long dashed lines represent species found at CL2. See Fig. S1 and Table S1 for full site descriptions (AR, CL1, CL2, USA).

alone (Fig. 5). The only case where litter depth explained more variance than $P$. contorta cover was for forb cover at CL2 (Araucaria araucana forest). In all cases, a significant amount of variance was explained jointly by $P$. contorta cover and litter depth (Fig. 5).

\section{DISCUSSION}

Pinus contorta cover was negatively correlated with plant species richness and cover at every study site (except plant cover at CL2), suggesting that pine invasion impacts on species richness and cover are similar in native and introduced ranges. However, species composition and individual species cover were more affected by $P$. contorta invasion in the introduced than native range. Additionally, invasions reach high levels of $P$. contorta cover more quickly in the introduced range than in the native range due to higher growth rates (Taylor et al., 2016). Therefore, although the relationships between $P$. contorta cover and plant species richness and cover were similar between sites, the declines in these properties may occur faster in the introduced than native range.
The negative correlation between $P$. contorta cover and species richness agrees with previous studies in New Zealand (Ledgard \& Paul, 2008) and Chile (Urrutia et al., 2013; Franzese, J. \& Pauchard, A., pers. comm.). Thus, there is mounting evidence that pine invasions into adjacent habitats will lead to declines in native plant species richness. Pinus contorta cover explained more of the decline in richness at the introduced steppe sites dominated by grass and shrubs where trees are likely a novel life-form (AR; CL1) than at the introduced forested site (CL2) or in the native range (USA). Species in the steppe are likely less tolerant of shade and litter accumulation than those in the A. araucana forest. We saw a consistent decline in richness with increases in $P$. contorta cover, unlike the hump-shaped response observed with Pinus nigra invasions in New Zealand (Dickie et al., 2011). Neither ours nor the New Zealand study identified a threshold at which species richness changed rapidly, suggesting that pine's influence on species richness scales with invader abundance and tipping points are unlikely. Although species richness declined with increasing $P$. contorta cover, at most sites we did not see a significant decrease in Shannon diversity. This finding contradicts other studies, with a broader range of species, that found lower diversity in invaded plots than in non-invaded plots (Hejda et al., 2009; Vilà et al., 2011).

Contrary to expectations, the rate of species loss associated with increasing $P$. contorta cover was the same in the native and introduced ranges. Other studies examining species richness associated with invasive species in their introduced and native ranges found a neutral or positive relationship between the invader and species richness in the native range (Inderjit et al., 2011; Kaur et al., 2012; Shah et al., 2014). Our results may differ because we assessed species richness associated with an active $P$. contorta invasion in the native range, whereas in other studies, the target species was invading in the introduced but not native range. Similar decreases in species richness in native plant communities following $P$. contorta invasion, and native woody encroachment in general, have also been observed (Haugo \& Halpern, 2007; Ratajczak et al., 2012). Therefore, results from this study and previous work suggest that conifer invasion of treeless areas is likely to decrease species richness, even in the native range.

Relative total plant cover decreased significantly with increasing $P$. contorta cover at the same rate in all sites. At all the grassland or shrubland sites, the dominant life-form (grass in CL1 and shrubs in AR and USA) declined significantly with higher $P$. contorta cover. Additionally, at all introduced sites, cover of dominant species had negative relationships with $P$. contorta cover. Changes in the dominant life-forms and species, as a result of invasion, will likely alter litter quantity and quality, which could result in cascading effects on belowground communities (Bardgett \& Wardle, 2010; Dickie et al., 2011). The switch from grasslands or shrublands to areas with high tree cover and little shrub or grass cover in AR, CL1 and USA, may also affect animal communities that depend on grass and shrubs for habitat (Pawson et al., 2010). The only site with native forest (CL2) 
Figure 3 Relationship between Pinus contorta cover and plant cover by lifeform and total plant cover at introduced (AR (a), CL1 (b), CL2 (c)) and native (USA (d)) sites. Only lines for relationships between Pinus contorta cover and life-forms that were significant at the $P=0.05$ level (Table 1) are shown. Dashed lines and triangles represent forb cover, dotted lines and circles represent grass cover, dot dashed lines and squares represent shrub cover, and solid lines and asterisks represent total plant cover. See Fig. S1 and Table S1 for full site descriptions (AR, CL1, CL2, USA).
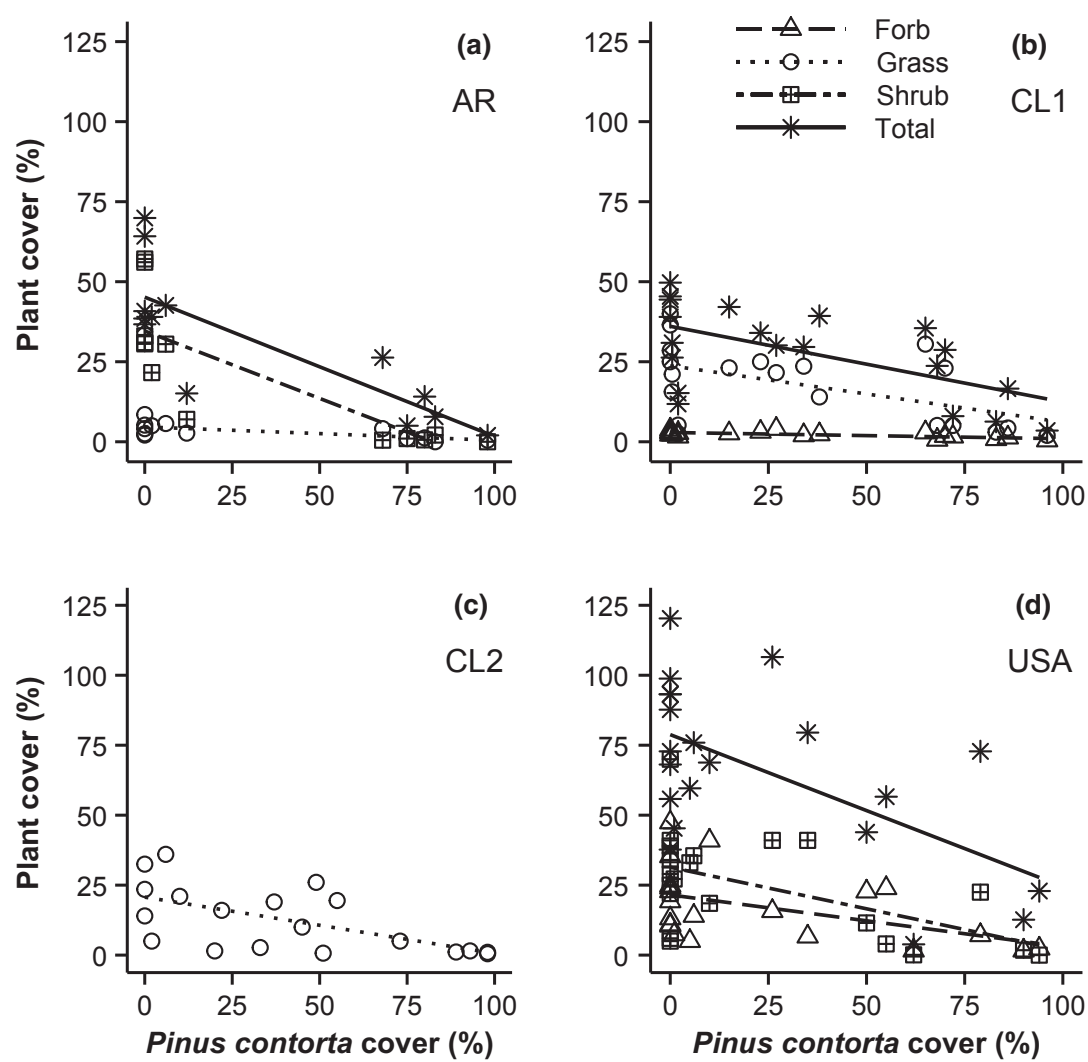

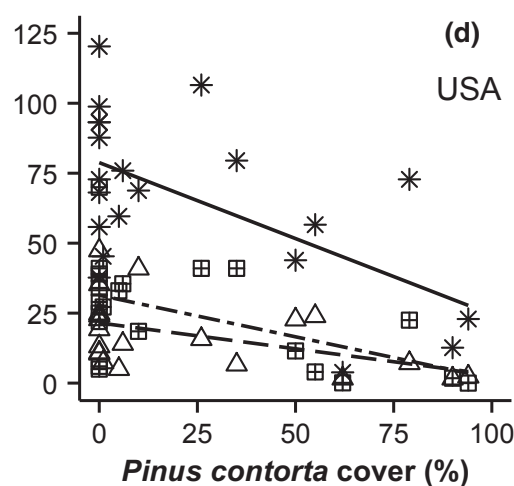

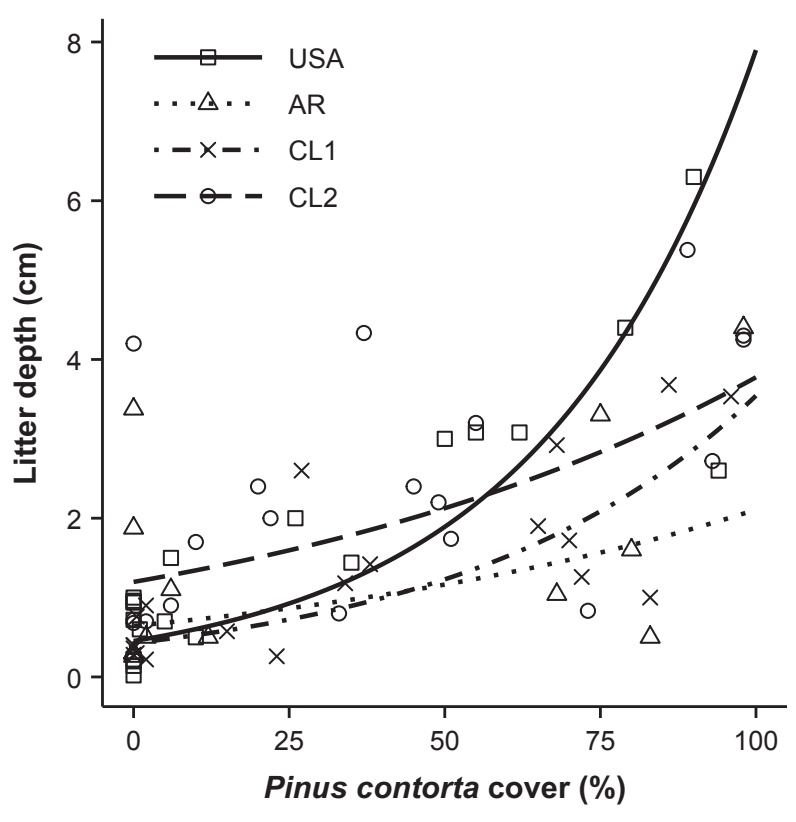

Figure 4 Litter depth and cover of Pinus contorta at the three introduced (AR, CL1, CL2) and one native (USA) sites, with the fitted lines from the linear model of the natural log of litter depth (back transformed to original scale). Solid line and squares represent USA, dotted line and triangles represent AR, dot dashed line and x's represent CL1, and long dashed line and circles represent CL2. See Fig. S1 and Table S1 for full site descriptions (AR, CL1, CL2, USA). showed no significant decline in total plant cover with increasing $P$. contorta cover, potentially because many native species growing in this forested site are shade tolerant. Another study also found less impact of $P$. contorta invasion on plant communities in an A. araucana forest than in a Patagonian steppe site (Franzese, J. \& Pauchard, A., pers. comm.). A trend of greater invader impact on species richness in shrublands than forests has been observed in Mediterranean-type ecosystems as well (Gaertner et al., 2009). Our results support the concept that impacts on plant communities depend on the traits of both the invader and the native communities (Levine et al., 2003; Maron \& Marler, 2008; Kumschick et al., 2015).

Impacts on species composition and individual species differed between the native and introduced range, suggesting that species richness alone is not the best metric to understand plant community change following non-native plant invasions (Parker et al., 1999). The most pronounced differences in plant species composition across the invasion gradient in our study were observed in the introduced range (Table 2). Cover of 19 individual species declined as $P$. contorta cover increased in the introduced range, while in the native range no individual species had a significant negative relationship with $P$. contorta cover (Fig. 2; Table S3). This difference between native and introduced ranges is exemplified by the grass genus Festuca, which was the most abundant grass genus at all sites, but only declined in abundance with increasing $P$. contorta cover in the introduced range 


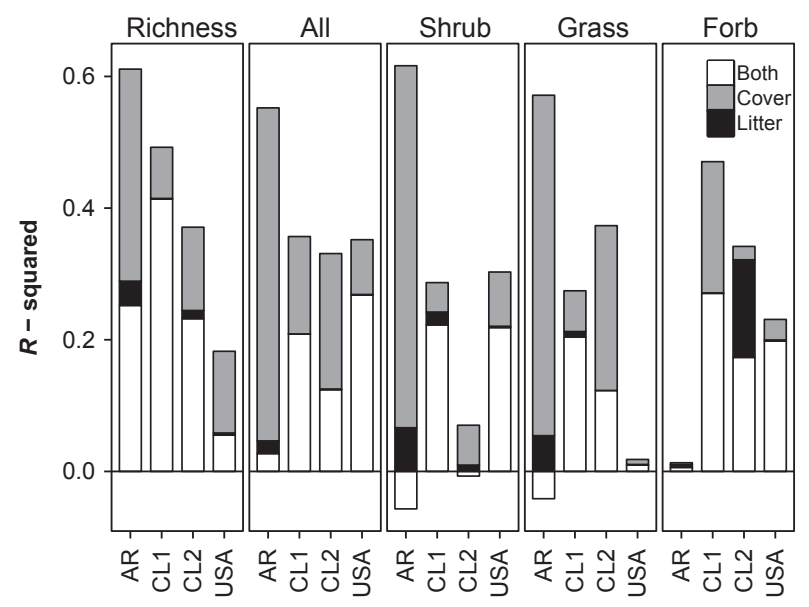

Figure 5 Results from the commonality analysis showing the percentage of the variance explained (R-squared, also known as the coefficient of determination) by either Pinus contorta cover or litter depth, or shared explanatory power due to collinearity, in the full model for each site. The responses include relative species richness (richness), all plant cover (All), shrub cover, grass cover and forb cover for each site. See Fig. S1 and Table S1 for full site descriptions (AR, CL1, CL2, USA).

(Fig. S2). Although species with high or intermediate abundance were more likely to decline with $P$. contorta invasion in the introduced than native range, there were locally rare species at the USA site that were sensitive to invasion (Table S2). Overall, differences in the impacts on species composition and individual species cover between native and introduced ranges suggest that Rocky Mountain grassland and shrubland communities, which have a long history of co-evolution with pines, may be less fundamentally altered by pine invasions. While invaded areas will likely experience a decline in species richness, species composition is expected to remain similar between invaded and uninvaded areas, at least for the first 50 years of invasion.

We saw little colonization by forest understorey species in P. contorta invaded plots in the native range. This observation differs from a study in Oregon, USA, in which native conifer invasion into subalpine meadows was associated with colonization of forest understorey species within two decades of tree establishment (Haugo \& Halpern, 2007). Perhaps such spread of forest understorey species at our USA site requires more than 50 years. Given that the Pinaceae is a novel family in Patagonia, it is unclear whether understorey species from native Nothofagus forest will colonize pinedominated forest, especially in the steppe (AR and CL1) where dispersal distances to the nearest forest may be long.

Several studies have found increased exotic species richness correlated with the presence of an invasive species in the introduced range (Kaur et al., 2012; Shah et al., 2014). We saw no support for this type of 'invasional meltdown' (Simberloff \& Von Holle, 1999; Dickie et al., 2014). However, a study in New Zealand found only exotic species persisting in the understorey of a $P$. contorta invasion 30 years after introduction (Ledgard \& Paul, 2008). Another study in New Zealand found that legacy impacts from pine invasions on soil processes promoted exotic grasses and forbs (Dickie et al., 2014). Therefore, the potential for P. contorta to promote invasion by herbaceous exotic species is not consistent between sites.

Often native communities are altered as a result of the different litter quantity or quality from exotic plants (Skurski et al., 2014). The sharpest increase in litter depth with increasing $P$. contorta cover was seen in the native range (USA; Fig. 4), potentially because invasions in the United States are at least 15 years older than invasions in the introduced range, so there has been more time for litter to accumulate. Alternatively, the deeper litter could be due to differences in decomposition rates related to the colder conditions in Montana (USA) than the Southern Hemisphere sites (Table S1). The changes in litter depth and quality may result in changes to soil processes or biotic communities (Dehlin et al., 2008; Dickie et al., 2014; de Oliveira et al., 2014). Increased litter abundance may also create a more continuous wildfire fuel bed in the steppe ecosystems where traditionally bareground patches have limited fire size (Baker, 2009; Paritsis et al., 2013).

Although litter accumulation is likely a mechanism driving impact, the results of our commonality analysis show that $P$. contorta cover alone explains more of the variance in species richness and plant cover than does litter depth alone. Therefore, increased shade is a strong mechanism causing changes in the plant community; although as litter accumulates over time, as these young pine trees age, litter depth and influence on biogeochemical processes could become more important in explaining native plant response. At the forested site (CL2), a decline in forb cover was more related to litter depth than P. contorta cover, potentially because forb species at this site may be adapted to low light situations, whereas pine litter chemistry likely differs from native species litter. In fact, Pinus ponderosa litter limited germination of several native Patagonian grass species (Raffaele \& Schlichter, 2000). At all sites, a large amount of variability in species richness and plant cover was jointly explained by $P$. contorta cover and litter depth. The overlap in explanatory power between litter depth and canopy cover is likely because litter is a measure of leaf area index which also represents shade. Therefore, these results highlight the need for manipulative experiments to separate the mechanisms of invader impacts.

Our results, along with those of previous studies, suggest that pine invasions will likely have significant impacts on plant communities in native and introduced ranges. We found that high $P$. contorta cover led to a decline in species richness whether it occurred in its native or introduced range. Impacts on native communities scaled with $P$. contorta abundance and no thresholds were found beyond which rapid declines in species richness or cover occurred. Contrary to previous biogeographic studies of plant invasion impacts, trends in species richness and plant cover were similar in the 
introduced and native ranges. Thus, biogeographic novelty alone does not govern all aspects of invader impact. Presence of a novel life-form and specific species traits may determine invader impact on recipient plant communities. Nonetheless, fundamental components of the plant communities, such as species composition, were more altered by pine invasions in the introduced than native range. Therefore, for some characteristics, native invaders may have less capacity than exotic invaders to cause significant impacts. These results highlight the need to examine multiple metrics of plant communities in order to fully understand invader impacts. In addition, to elucidate the importance of specific mechanisms of pine invasion impact on native ecosystems, management of pine invasions could be integrated with experimentation by designing treatments and follow-up monitoring.

\section{ACKNOWLEDGEMENTS}

We thank David McWethy, Hannah Funke, Maria Theresa Jessen and Sam Wall for field assistance and Pablo Bravo, Jonathan Urrutia and Jorgelina Franzese for help with species identification. We thank Cathy Whitlock, David McWethy, and three anonymous referees for helpful comments on the manuscript. KTT and BDM were funded by NSF-WildFIRE PIRE, OISE 09667472. AP was funded by Fondecyt grants 1100792 and 1140485, and the Institute of Ecology and Biodiversity with the grants by the Ministry of the Economy ICM P05-002 and CONICYT PFB-23. MAN was funded by Biosilva \#5 from MAGyP of Argentina.

\section{REFERENCES}

Baker, W.L. (2009) Fire Ecology in Rocky Mountain Landscapes. Island Press, Washington, DC.

Bardgett, R.D. \& Wardle, D.A. (2010) Aboveground - Belowground Linkages. Oxford University Press, Oxford.

Blossey, B. \& Notzold, R. (1995) Evolution of increased competitive ability in invasive nonindigenous plants - A hypothesis. Journal of Ecology, 83, 887-889.

Brewer, J.S. (1998) Patterns of plant species richness in a wet slash-pine (Pinus elliottii) savanna. Journal of the Torrey Botanical Society, 125, 216-224.

Callaway, R.M. \& Aschehoug, E.T. (2000) Invasive plants versus their new and old neighbors: a mechanism for exotic invasion. Science, 290, 521-523.

Callaway, R.M., Cipollini, D., Barto, K., Thelen, G.C., Hallett, S.G., Prati, D., Stinson, K. \& Klironomos, J. (2008) Novel weapons: invasive plant suppresses fungal mutualists in America but not in its native Europe. Ecology, 89, 10431055.

Callaway, R.M., Schaffner, U., Thelen, G.C., Khamraev, A., Juginisov, T. \& Maron, J.L. (2012) Impact of Acroptilon repens on co-occurring native plants is greater in the invader's non-native range. Biological Invasions, 14, 11431155 .
Camarillo, S.A., Stovall, J.P. \& Sunda, C.J. (2015) The impact of Chinese tallow (Triadica sebifera) on stand dynamics in bottomland hardwood forests. Forest Ecology and Management, 344, 10-19.

Constán-Nava, S., Soliveres, S., Torices, R., Serra, L. \& Bonet, A. (2015) Direct and indirect effects of invasion by the alien tree Ailanthus altissima on riparian plant communities and ecosystem multifunctionality. Biological Invasions, 17, 1095-1108.

Dehlin, H., Peltzer, D.A., Allison, V.J., Yeates, G.W., Nilsson, M.-C. \& Wardle, D.A. (2008) Tree seedling performance and below-ground properties in stands of invasive and native tree species. New Zealand Journal of Ecology, 32, 6779.

Dickie, I.A., Yeates, G.W., St John, M.G., Stevenson, B.A., Scott, J.T., Rillig, M.C., Peltzer, D.A., Orwin, K.H., Kirschbaum, M.U.F., Hunt, J.E., Burrows, L.E., Barbour, M.M. \& Aislabie, J. (2011) Ecosystem service and biodiversity tradeoffs in two woody successions. Journal of Applied Ecology, 48, 926-934.

Dickie, I.A., St John, M.G., Yeates, G.W., Morse, C.W., Bonner, K.I., Orwin, K. \& Peltzer, D.A. (2014) Belowground legacies of Pinus contorta invasion and removal result in multiple mechanisms of invasional meltdown. AoB Plants, 6, plu056.

Ehrenfeld, J.G. (2003) Effects of exotic plant invasions on soil nutrient cycling processes. Ecosystems, 6, 503-523.

Farley, K.A., Jobbagy, E.G. \& Jackson, R.B. (2005) Effects of afforestation on water yield: a global synthesis with implications for policy. Global Change Biology, 11, 1565-1576.

Fernandez, M.E., Gyenge, J. \& Schlichter, T. (2009) Water flux and canopy conductance of natural versus planted forests in Patagonia, South America. Trees-Structure and Function, 23, 415-427.

Gaertner, M., Den Breeyen, A., Hui, C. \& Richardson, D.M. (2009) Impacts of alien plant invasions on species richness in Mediterranean-type ecosystems: a meta-analysis. Progress in Physical Geography, 33, 319-338.

Griffiths, R., Madritch, M. \& Swanson, A. (2005) Conifer invasion of forest meadows transforms soil characteristics in the Pacific Northwest. Forest Ecology and Management, 208, 347-358.

Haugo, R.D. \& Halpern, C.B. (2007) Vegetation responses to conifer encroachment in a western Cascade meadow: a chronosequence approach. Canadian Journal of BotanyRevue Canadienne De Botanique, 85, 285-298.

Hejda, M., Pyšek, P. \& Jarosik, V. (2009) Impact of invasive plants on the species richness, diversity and composition of invaded communities. Journal of Ecology, 97, 393-403.

Hulme, P.E., Pyšek, P., Jarošík, V., Pergl, J., Schaffner, U. \& Vilà, M. (2013) Bias and error in understanding plant invasion impacts. Trends in Ecology \& Evolution, 28, 212218.

Inderjit, Evans, H., Crocoll, C., Bajpai, D., Kaur, R., Feng, Y.-L., Silva, C., Treviño Carreón, J., Valiente-Banuet, A., Gershenzon, J. \& Callaway, R.M. (2011) Volatile chemicals 
from leaf litter are associated with invasiveness of a Neotropical weed in Asia. Ecology, 92, 316-324.

Jakubos, B. \& Romme, W.H. (1993) Invasion of sub-alpine meadows by lodgepole pine in Yellowstone National Park, Wyoming, USA. Arctic and Alpine Research, 25, 382-390.

Kaur, R., Gonzales, W.L., Daniel Llambi, L., Soriano, P.J., Callaway, R.M., Rout, M.E., Gallaher, T.J. \& Inderjit (2012) Community impacts of Prosopis juliflora invasion: biogeographic and congeneric comparisons. PLOS ONE, 7, e44966.

Klironomos, J.N. (2002) Feedback with soil biota contributes to plant rarity and invasiveness in communities. Nature, 417, 67-70.

Kumschick, S., Gaertner, M., Vilà, M., Essl, F., Jeschke, J.M., Pyšek, P., Ricciardi, A., Bacher, S., Blackburn, T.M., Dick, J.T.A., Evans, T., Hulme, P.E., Kühn, I., Mrugała, A., Pergl, J., Rabitsch, W., Richardson, D.M., Sendek, A. \& Winter, M. (2015) Ecological impacts of alien species: quantification, scope, caveats, and recommendations. BioScience, 65, 55-63.

Langdon, B., Pauchard, A. \& Aguayo, M. (2010) Pinus contorta invasion in the Chilean Patagonia: local patterns in a global context. Biological Invasions, 12, 3961-3971.

Lazzaro, L., Giuliani, C., Benesperi, R., Calamassi, R. \& Foggi, B. (2015) Plant species loss and community nestedness after leguminous tree Acacia pycnantha invasion in a Mediterranean ecosystem. Folia Geobotanica, 50, 229-238.

Ledgard, N.J. \& Paul, T.S.H. (2008) Vegetation successions over 30 years of high country grassland invasion by Pinus contorta. New Zealand Plant Protection, 61, 98-104.

Lesica, P. (2012) Manual of Montana Vascular Plants. Brit Press, Fort Worth, TX.

Levine, J.M., Vilà, M., D’Antonio, C.M., Dukes, J.S., Grigulis, K. \& Lavorel, S. (2003) Mechanisms underlying the impacts of exotic plant invasions. Proceedings of the Royal Society B: Biological Sciences, 270, 775-781.

Maron, J.L. \& Marler, M. (2008) Effects of native species diversity and resource additions on invader impact. The American Naturalist, 172, S18-S33.

Ni, G.-Y., Schaffner, U., Peng, S.-L. \& Callaway, R.M. (2010) Acroptilon repens, an Asian invader, has stronger competitive effects on species from America than species from its native range. Biological Invasions, 12, 3653-3663.

Nilsson, C., Engelmark, O., Cory, J., Forsslund, A. \& Carlborg, E. (2008) Differences in litter cover and understory flora between stands of introduced lodgepole pine and native scots pine in Sweden. Forest Ecology and Management, 255, 1900-1905.

Nuñez, M.A., Hayward, J., Horton, T.R., Amico, G.C., Dimarco, R.D., Barrios-Garcia, M.N. \& Simberloff, D. (2013) Exotic mammals disperse exotic fungi that promote invasion by exotic trees. PLoS ONE, 8, e66832.

Oksanen, J., Blanchet, F.G., Kindt, R., Legendre, P., Minchin, P.R., O’Hara, R.B., Simpson, G.L., Solymos, P., Stevens, M.H.H. \& Wagner, H. (2013) vegan: Community Ecology
Package. R package version 2.0-10. http://CRAN.R-project.org/package $=$ vegan (accessed 25 July 2015).

de Oliveira, S.M., Boll, P.K., Baptista, V.D. \& Leal-Zanchet, A.M. (2014) Effects of pine invasion on land planarian communities in an area covered by Araucaria moist forest. Zoological Studies, 53, 19.

Paritsis, J. \& Aizen, M.A. (2008) Effects of exotic conifer plantations on the biodiversity of understory plants, epigeal beetles and birds in Nothofagus dombeyi forests. Forest Ecology and Management, 255, 1575-1583.

Paritsis, J., Holz, A., Veblen, T.T. \& Kitzberger, T. (2013) Habitat distribution modeling reveals vegetation flammability and land use as drivers of wildfire in SW Patagonia. Ecosphere, 4, art53.

Parker, I.M., Simberloff, D., Lonsdale, W.M., Goodell, K., Wonham, M., Kareiva, P.M., Williamson, M.H., Von Holle, B., Moyle, P.B., Byers, J.E. \& Goldwasser, L. (1999) Impact: toward a framework for understanding the ecological effects of invaders. Biological Invasions, 1, 3-19.

Parker, J.D., Torchin, M.E., Hufbauer, R.A. et al. (2013) Do invasive species perform better in their new ranges? Ecology, 94, 985-994.

Patten, D.T. (1969) Succession from sagebrush to mixed conifer forest in Northern Rocky Mountains. American Midland Naturalist, 82, 229-240.

Pawson, S.M., McCarthy, J.K., Ledgard, N.J. \& Didham, R.K. (2010) Density-dependent impacts of exotic conifer invasion on grassland invertebrate assemblages. Journal of Applied Ecology, 47, 1053-1062.

Peña, E., Hidalgo, M., Langdon, B. \& Pauchard, A. (2008) Patterns of spread of Pinus contorta Dougl. ex Loud. invasion in a Natural Reserve in southern South America. Forest Ecology and Management, 256, 1049-1054.

R Core Team. (2014) R: A Language and Environment for Statistical Computing version 3.1.1. R Foundation for Statistical Computing, Vienna, Austria. http://www.R-project.org.

Raffaele, E. \& Schlichter, T. (2000) Efectos de las plantaciones de pino ponderosa sobre la heterogeneidad de micrositios en estepas del noroeste patagónico. Ecología Austral, 10, 151-158.

Ratajczak, Z., Nippert, J.B. \& Collins, S.L. (2012) Woody encroachment decreases diversity across North American grasslands and savannas. Ecology, 93, 697-703.

Ray-Mukherjee, J., Nimon, K., Mukherjee, S., Morris, D.W., Slotow, R. \& Hamer, M. (2014) Using commonality analysis in multiple regressions: a tool to decompose regression effects in the face of multicollinearity. Methods in Ecology and Evolution, 5, 320-328.

Rejmánek, M. \& Richardson, D.M. (1996) What attributes make some plant species more invasive? Ecology, 77, 16551661.

Rejmánek, M. \& Richardson, D.M. (2013) Trees and shrubs as invasive alien species - 2013 update of the global database. Diversity and Distributions, 19, 1093-1094. 
Richardson, D.M. (ed.) (1998) Ecology and Biogeography of Pinus. Cambridge University Press, Cambridge.

Richardson, D.M. \& Bond, W.J. (1991) Determinants of plant distribution: evidence from pine invasions. The American Naturalist, 137, 639-668.

Richardson, D.M. \& Higgins, S.I. (1998) Pines as invaders in the southern hemisphere. Ecology and Biogeography of Pinus (ed.by D.M. Richardson), pp. 450-473. Cambridge University Press, Cambridge.

Rundel, P.W., Dickie, I.A. \& Richardson, D.M. (2014) Tree invasions into treeless areas: mechanisms and ecosystem processes. Biological Invasions, 16, 663-675.

Shackleton, R.T., Le Maitre, D.C., Van Wilgen, B.W. \& Richardson, D.M. (2015) The impact of invasive alien Prosopis species (mesquite) on native plants in different environments in South Africa. South African Journal of Botany, 97, 25-31.

Shah, M.A., Callaway, R.M., Shah, T., Houseman, G.R., Pal, R.W., Xiao, S., Luo, W., Rosche, C., Reshi, Z.A., Khasa, D.P. \& Chen, S. (2014) Conyza canadensis suppresses plant diversity in its nonnative ranges but not at home: a transcontinental comparison. New Phytologist, 202, 1286-1296.

Siemann, E. \& Rogers, W.E. (2001) Genetic differences in growth of an invasive tree species. Ecology Letters, 4, 514-518.

Simberloff, D. \& Von Holle, B. (1999) Positive interactions of nonindigenous species: invasional meltdown? Biological Invasions, 1, 21-32.

Simberloff, D., Nuñez, M.A., Ledgard, N.J., Pauchard, A., Richardson, D.M., Sarasola, M., Van Wilgen, B.W., Zalba, S.M., Zenni, R.D., Bustamante, R., Peña, E. \& Ziller, S.R. (2010) Spread and impact of introduced conifers in South America: lessons from other southern hemisphere regions. Austral Ecology, 35, 489-504.

Simberloff, D., Souza, L., Nuñez, M.A., Barrios-Garcia, M.N. \& Bunn, W. (2012) The natives are restless, but not often and mostly when disturbed. Ecology, 93, 598607.

Skurski, T.C., Rew, L.J. \& Maxwell, B.D. (2014) Mechanisms underlying nonindigenous plant impacts: a review of recent experimental research. Invasive Plant Science and Management, 7, 432-444.

Steers, R.J., Fritzke, S.L., Rogers, J.J., Cartan, J. \& Hacker, K. (2013) Invasive pine tree effects on northern coastal scrub structure and composition. Invasive Plant Science and Management, 6, 231-242.

Taylor, K.T., Maxwell, B.D., Pauchard, A., Nuñez, M.A., Peltzer, D.A., Terwei, A. \& Rew, L.J. (2016) Drivers of plant invasion vary globally: evidence from pine invasions within six ecoregions. Global Ecology and Biogeography, 25, 96-106.

Thorpe, A.S. \& Callaway, R.M. (2011) Biogeographic differences in the effects of Centaurea stoebe on the soil nitrogen cycle: novel weapons and soil microbes. Biological Invasions, 13, 1435-1445.
Thorpe, A.S., Thelen, G.C., Diaconu, A. \& Callaway, R.M. (2009) Root exudate is allelopathic in invaded community but not in native community: field evidence for the novel weapons hypothesis. Journal of Ecology, 97, 641-645.

Urrutia, J., Pauchard, A. \& Garcia, R.A. (2013) Differences in plant composition in an Araucaria araucana (Molina) K. Koch and Nothofagus antarctica (G. Forst.) Oerst. forest in a Pinus contorta Douglas ex Loudon invasion gradient. Gayana Botanica, 70, 92-100.

Vilà, M., Espinar, J.L., Hejda, M., Hulme, P.E., Jarošík, V., Maron, J.L., Pergl, J., Schaffner, U., Sun, Y. \& Pyšek, P. (2011) Ecological impacts of invasive alien plants: a metaanalysis of their effects on species, communities and ecosystems. Ecology Letters, 14, 702-708.

Zuloaga, F.O., Morrone, O. \& Belgrano, M.J. (2008) Catálogo de las Plantas Vasculares del Conosur (Argentina, Sur de Brasil, Chile, Paraguay y Uruguay). Monographs in Systematic Botany from the Missouri Botanical Garden, 107, St. Louis, MO.

\section{SUPPORTING INFORMATION}

Additional Supporting Information may be found in the online version of this article:

Figure S1 Photographs of Pinus contorta invasion at all study sites.

Table S1 Site descriptions.

Table S3 Results from the significant models of individual species cover as a function of Pinus contorta cover.

Figure S2 Relationship between Festuca spp. and Pinus contorta at all sites.

Table S2 List of all species recorded in each site.

\section{BIOSKETCH}

The research team is generally focused on understanding the processes driving the spatial distribution, dynamics, spread and impacts of non-native plant species, with a recent focus on pine invasions across the globe. K.T.T., B.D.M. and L.J.R. are part of the Weed and Invasive Plant Ecology and Management Group at Montana State University (http:// weedeco.msu.montana.edu).

Author contributions: K.T.T., B.D.M., A.P. and M.N. conceived of the ideas. B.D.M. funded the study. K.T.T. and B.D.M. collected the data. K.T.T. analysed the data with input from B.D.M. and L.J.R. K.T.T. wrote the first draft of the manuscript, and all authors contributed substantially to revisions.

Editor: Marcel Rejmanek 